\title{
Inferred changes in El Niño-Southern Oscillation variance over the past six centuries
}

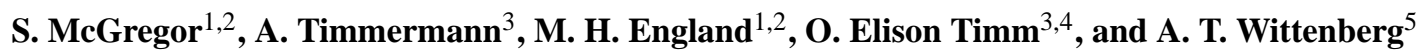 \\ ${ }^{1}$ Climate Change Research Centre, University of New South Wales, Sydney, Australia \\ ${ }^{2}$ ARC Centre of Excellence for Climate System Science, University of New South Wales, Sydney, Australia \\ ${ }^{3}$ International Pacific Research Center, University of Hawaii, Honolulu, Hawaii, USA \\ ${ }^{4}$ Department of Atmospheric and Environmental Sciences, University at Albany, Albany, NY, USA \\ ${ }^{5}$ Geophysical Fluid Dynamics Laboratory/NOAA, Princeton, New Jersey, USA
}

Correspondence to: S. McGregor (shayne.mcgregor@unsw.edu.au)

Received: 6 May 2013 - Published in Clim. Past Discuss.: 30 May 2013

Revised: 22 August 2013 - Accepted: 25 August 2013 - Published: 10 October 2013

\begin{abstract}
It is vital to understand how the El Niño-Southern Oscillation (ENSO) has responded to past changes in natural and anthropogenic forcings, in order to better understand and predict its response to future greenhouse warming. To date, however, the instrumental record is too brief to fully characterize natural ENSO variability, while large discrepancies exist amongst paleo-proxy reconstructions of ENSO. These paleo-proxy reconstructions have typically attempted to reconstruct ENSO's temporal evolution, rather than the variance of these temporal changes. Here a new approach is developed that synthesizes the variance changes from various proxy data sets to provide a unified and updated estimate of past ENSO variance. The method is tested using surrogate data from two coupled general circulation model (CGCM) simulations. It is shown that in the presence of dating uncertainties, synthesizing variance information provides a more robust estimate of ENSO variance than synthesizing the raw data and then identifying its running variance. We also examine whether good temporal correspondence between proxy data and instrumental ENSO records implies a good representation of ENSO variance. In the climate modeling framework we show that a significant improvement in reconstructing ENSO variance changes is found when combining information from diverse ENSO-teleconnected source regions, rather than by relying on a single well-correlated location. This suggests that ENSO variance estimates derived from a single site should be viewed with caution. Finally, synthesizing existing ENSO reconstructions to arrive at a better estimate of past ENSO variance changes, we find robust
\end{abstract}

evidence that the ENSO variance for any $30 \mathrm{yr}$ period during the interval $1590-1880$ was considerably lower than that observed during 1979-2009.

\section{Introduction}

The El Niño-Southern Oscillation (ENSO) is characterized by variations in sea surface temperature (SST) in the eastern tropical Pacific, causing changes in ocean currents and atmospheric circulation patterns globally. Related shifts in wind and rainfall patterns can lead to changes in extreme events including flooding, droughts, and tropical cyclone activity (Chan, 1985; Larkin and Harrison, 2002; Nicholls, 1985; Power et al., 1999). ENSO has been shown to exhibit significant multi-decadal variability in its strength and frequency throughout the instrumental period (Power, et al., 1999; Timmermann et al., 2003; Zhang et al., 1998), with additional longer-term variability reported in proxy data ( $\mathrm{Li}$ et al., 2011; Wolff et al., 2011; Emile-Geay et al., 2013b).

Characterizing ENSO's long-term changes in frequency, magnitude and duration has been hampered by the fact that reliable instrumental records cover a period of less than $150 \mathrm{yr}$. This period is too brief to capture the range of longterm changes in ENSO frequency, magnitude and duration (Wittenberg, 2009). Multi-century paleo-climate reconstructions derived from monthly to annually resolved tree rings, ice cores, lake sediments and coral records can be used to extend the observational record and to further quantify ENSO's 
sensitivity to external radiative perturbations in the "backdrop" of its internally generated variability (Federov and Philander, 2000). Numerous attempts have been made to reconstruct ENSO variability back in time using various paleoproxy archives (e.g., see Table 1 and Fig. 1).

While there appears to be large-scale coherence among the reconstructed time series, the variance changes from these reconstructions differ considerably. For instance, half of the ENSO reconstructions (reconstruction numbers 1, 2, 3, 4, 6, 13 and 14 from Table 1 ) suggest that the ENSO variability recorded during the Little Ice Age (LIA, $\sim 1550-1880$ ) was at times higher than reconstructions of most recent ENSO activity. The remaining reconstructions suggest that ENSO variability of the LIA failed to match recent levels. Thus, there is ambiguity among the reconstructions as to where current levels of ENSO variability are placed in the context of the past $\sim 600 \mathrm{yr}$, which reduces our confidence in how well any individual reconstruction can in fact capture lowfrequency ENSO variance modulations.

In this study we use two multi-century coupled general circulation model (CGCM) simulations to examine an assumption made implicitly by many paleo-reconstruction studies i.e., that a good temporal correspondence between a given climate variable and ENSO translates also into a high correlation between multi-decadal variance changes in this variable and in ENSO (e.g., McGregor et al., 2010; Wilson et al., 2010; $\mathrm{Li}$ et al., 2011, 2013). We also test a simple method to extract the common ENSO variance modulation signal using proxies from a variety of ENSO-teleconnected locations that is robust against small dating errors, unlike previous proxy analyses. We then use this method to identify the common variance signal in a number of pre-defined proxy-based ENSO reconstructions and a range of single-station rainfall and temperature proxies over the past $600 \mathrm{yr}$.

\section{Simulations}

The CGCM simulations used in this study are the externally forced last-millennium (850-1850) simulation of the Community Climate System Model, version 4 (hereafter CCSM4, Landrum et al., 2013), and a $2000 \mathrm{yr}$ pre-industrial control run of the Geophysical Fluid Dynamics Laboratory (GFDL)CM2.1 model with no changes in external forcings (Wittenberg, 2009). Note that prior to any analysis, annual mean (July-June) values of model precipitation and surface temperature $\left(T_{\mathrm{S}}\right)$ data from the model simulations are calculated, and the resulting time series are filtered with a $10 \mathrm{yr}$ highpass Butterworth filter to isolate the variability in the classical ENSO band of 2-8 yr.

It is noted that the experimental design differs between these two coupled model simulations: the CCSM4 simulation includes estimates of observed time-varying forcing, such as solar, volcanic aerosols, and greenhouse gases, whereas CM2.1 includes these external forcings fixed at 1860

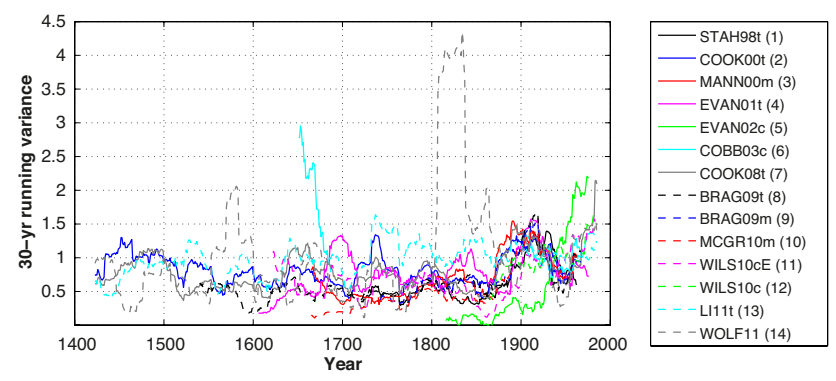

Fig. 1. The running variance of each of the $10 \mathrm{yr}$ high-pass-filtered ENSO reconstructions (reconstruction names and numbers correspond to those in Table 1). Note the individual reconstruction time series were normalized over the period 1900-1977 prior to calculating the running variance in a $30 \mathrm{yr}$ sliding window. Each running variance time series is then adjusted by adding a constant, such that their mean running variance over the period 1900-1977 matches that of the observed ENSO signal (defined as high-pass-filtered surface temperature averaged over the Niño 3.4 region) over the same period.

levels. However, we expect the results of this multi-model analysis to establish the robustness of the results presented in this manuscript, as the study of Landrum et al. (2013) has demonstrated that the addition of last-millennium timevarying forcing's had no significant impact on the various internal modes of simulated climate variability in CCSM4 (e.g., ENSO, the North Atlantic Oscillation, Pacific Decadal Oscillation).

The atmospheric component of the CCSM4 simulation uses a uniform horizontal resolution of 1.258 in latitude by 0.98 in longitude, and has 26 layers in the vertical (Neale et al., 2013). The ocean model, which is based on version 2 of the Parallel Ocean Program model (Smith et al., 2010), uses the standard ocean grid with a displaced grid North Pole, nominal $1^{\circ}$ horizontal resolution (uniform 1.18 in longitude, variable in latitude from $0.27^{\circ}$ at the Equator to $0.54^{\circ}$ at $33^{\circ}$ latitude), and 60 levels in the vertical (Danabasoglu et al., 2012). The land surface model adopts the same horizontal resolution as CAM4, while the sea ice model uses the same horizontal grid as the ocean component (Landrum et al., 2013). CCSM4's simulation of tropical Pacific climate is described extensively in Deser et al. (2012). The seasonal evolution, phase asymmetry and teleconnections of the modeled ENSO are consistent with observations.

The CM2.1 ocean model is based on Modular Ocean Model version 4 (MOM4) code, with 50 vertical levels and a $1^{\circ} \times 1^{\circ}$ horizontal resolution that telescopes to $1 / 3^{\circ}$ meridional spacing near the Equator. The atmospheric component has 24 vertical levels, $2^{\circ}$ latitude by $2.5^{\circ}$ longitude horizontal resolution. The land surface model has the same horizontal resolution as the atmosphere. Full model details can be found in Delworth et al. (2006). ENSO variability in CM2.1 exhibits multi-decadal fluctuations in amplitude (Wittenberg, 2009; Ogata et al., 2013), and the irregular ENSO mode is 
Table 1. Existing ENSO reconstructions employed in this study. Note that these ENSO reconstructions have at least annual resolution and are pre-screened such that they have a correlation of at least 0.5 with the annual mean (July-June) observations of ENSO, represented by Niño 3.4 area-averaged $\left(5^{\circ} \mathrm{S}-5^{\circ} \mathrm{N}, 120^{\circ} \mathrm{W}-170^{\circ} \mathrm{W}\right)$ SST anomalies (SSTA; Table 2). This correlation cutoff ensures the ENSO reconstruction provides a skillful estimate of ENSO variability, at least over the instrumental epoch.

\begin{tabular}{llllll}
\hline No. & Label & Reference & Period & Proxy type & Source region \\
\hline 1 & STAH98t & Stahle et al. (1998) & $1706-1997$ & Tree ring & Pacific Basin \\
2 & COOK00t & Cook (2000) & $1408-1978$ & Tree ring & North America \\
3 & MANN00m & Mann et al. (2000) & $1650-1990$ & Mixed & Near global (tropics) \\
4 & EVAN01t & Evans et al. (2001) & $1590-1990$ & Tree ring & America \\
5 & EVAN02c & Evans et al. (2002) & $1800-1990$ & Coral & Indo-Pacific Basin \\
6 & COBB03c & Cobb et al. (2003) & $1635-1703 \&$ 1886-1998 & Coral & Central equatorial Pacific \\
7 & COOK08t & Cook et al. (2008) & $1300-1978$ & Tree ring & North America \\
8 & BRAG09t & Braganza et al. (2009) & $1525-1982$ & Tree ring & Pacific Basin \\
9 & BRAG09m & Braganza et al. (2009) & $1727-1982$ & Mixed & Pacific Basin \\
10 & MCGR10m & McGregor et al. (2010) & $1650-1977$ & Mixed & Near global (tropics) \\
11 & WILS10cE & Wilson et al. (2010) & $1850-1998$ & Coral & Eastern equatorial Pacific \\
12 & WILS10c & Wilson et al. (2010) & $1540-1998$ & Coral & Indo-Pacific Basin \\
13 & LI11 & Li et al. (2011) & $900-2002$ & Tree ring & North America \\
14 & WOLF11 & Wolff et al. (2011) & $1208-2005$ & Lake varves & East Africa \\
\hline
\end{tabular}

characterized by periods between 2 and $5 \mathrm{yr}$. SST anomalies in the eastern equatorial Pacific are skewed toward warm events, consistent with observations. The evolution of ENSO subsurface temperatures is also realistically represented, as are ENSO's teleconnections. Tropical climate variability in CM2.1 is extensively described in Wittenberg et al. (2006), Capotondi et al. (2006), Kug et al. (2010), and Karamperidou et al. (2013).

\section{Methods}

\subsection{Testing the running variance implications of a good temporal correlation}

The fact that there is such a wide spread between the running variances of the individual ENSO reconstructions (Fig. 1) raises the question whether a good temporal correspondence between a given regional climate variable and ENSO can be used to imply that the variable will also provide a good representation of ENSO variance. We use output from the CCSM4 and CM2.1 models to address this question. The correlation between the simulated running variance of $T_{\mathrm{S}}$ in CM2.1 and the running variance of Nino 3.4 area-averaged $\left(5^{\circ} \mathrm{S}\right.$ $\left.5^{\circ} \mathrm{N}, 120^{\circ} \mathrm{W}-170^{\circ} \mathrm{W}\right) T_{\mathrm{S}}$ anomalies, hereafter referred to as ENSO running variance (Fig. 2a, shading), is quite similar to the correlation between the simulated $T_{\mathrm{S}}$ and ENSO (Fig. 2a, contours). Note that to focus on ENSO's multidecadal changes the running variance in this study is calculated using a $30 \mathrm{yr}$ sliding window. The pattern correlation between these two correlation maps amounts to 0.79 $\left(r^{2}=0.63\right)$. Similar results are also obtained for the CCSM4 simulation (comparing Fig. 2c contours versus shading). The corresponding pattern correlation is $0.70\left(r^{2}=0.49\right)$. In this modeling framework, our results suggest that a large absolute value of the correlation between $T_{\mathrm{S}}$ and ENSO provides a clear indication that the running variance of $T_{\mathrm{S}}$ will track that of ENSO.

However, calculating the correlation between the CM2.1 simulated precipitation running variance with ENSO running variance (Fig. 2b, shading), and comparing this with the absolute value of the correlation between the simulated precipitation and ENSO (Fig. 2b, contours) reveals some key differences in the tropical Pacific. For example, in the western tropical Pacific the correlation between precipitation and ENSO is high, with values falling between the 0.45 and 0.75 contours. However, the correlation between precipitation running variance and ENSO running variance in this region is near zero and even slightly negative, indicating that an increase in ENSO variance may be totally missed, or even displayed as a decrease in variance, by precipitation in this region. Similar differences are also seen for the CCSM4 simulation (comparing Fig. 2d shading versus contours). We obtain pattern correlations between the temporal correlation maps of CM2.1 (i.e., comparing the shading versus contours in Fig. 2b) and CCSM4 (i.e., comparing the shading versus contours in Fig. 2d) that attain values of $0.67\left(r^{2}=0.45\right)$ and $0.55\left(r^{2}=0.31\right)$, respectively.

Figure 3 displays the 5th, 50th and 95th percentiles of the correlation coefficients calculated between the simulated precipitation running variance and ENSO running variance at the corresponding location, binned according to the correlation between simulated precipitation and ENSO. As expected from the differences between the two correlation maps in the tropical Pacific region (Fig. 2, shading versus contours), the 5th percentile curve reveals that having a strong correlation between precipitation and ENSO at a particular location 
a)

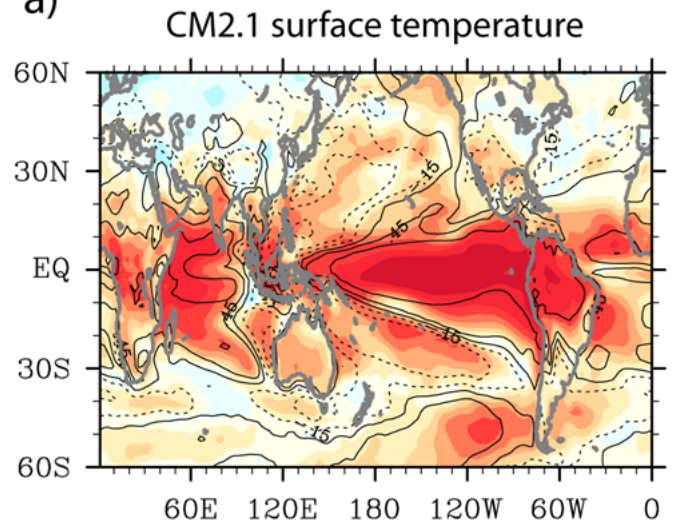

c)

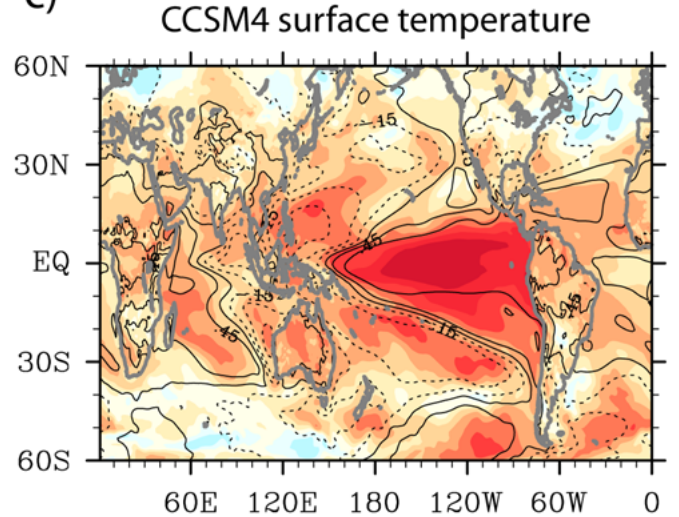

b)

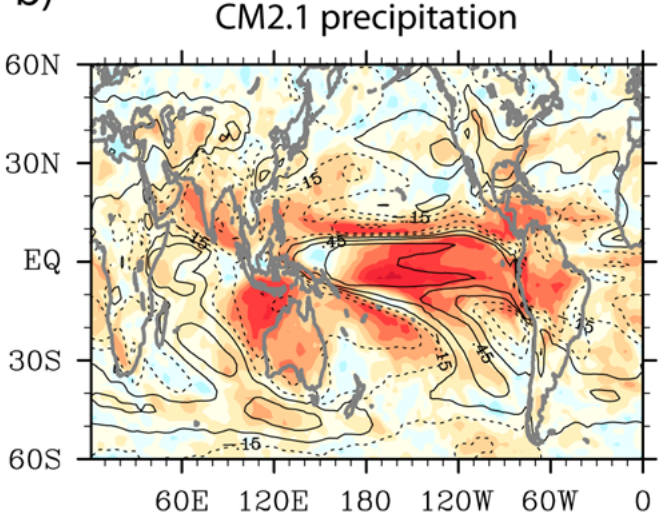

d)
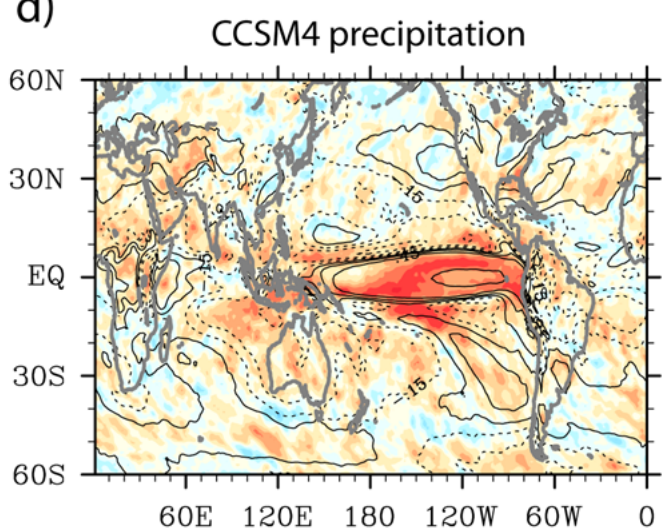

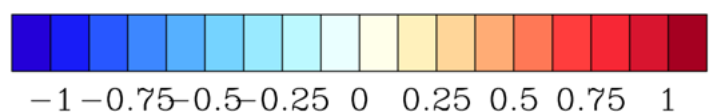

Fig. 2. Correlation between the running variance of the (a) simulated surface temperature $\left(T_{\mathrm{S}}\right)$ and (b) precipitation running variance with the running variance of the simulated ENSO index (defined as the area-averaged $T_{\mathrm{S}}$ in the Niño 3.4 region) in CM2.1. The overlying contours in panels (a) and (b) represent the correlations between simulated $T_{\mathrm{S}}$ and rainfall, respectively, with the simulated ENSO index. Contours are from -0.75 to 0.75 with a spacing of 0.3 and negative contours are dashed. (c) and (d) as in (a) and (b), respectively, but for CCSM4 model output.

does not guarantee a strong correlation between the precipitation running variance at that location and ENSO running variance. For instance, in CM2.1 if a simulated precipitation signal is selected that has an $r^{2}$ value of between 0.6 and 0.7 when compared with the simulated ENSO, there is a $10 \%$ chance that the precipitation running variance time series has an $r^{2}<0.1(r<0.31)$ when compared with ENSO running variance (Fig. 3a). This indicates either that (i) ENSO may influence the sign and timing of the rainfall change at this location - however, unrelated processes influence the magnitude of that change - or that (ii) the relationship between precipitation and ENSO at that location is highly non-linear.

We find that a strong correlation between a common precipitation time series, identified by calculating the median time series from multiple simulated precipitation time series sourced from different locations, and simulated ENSO is a much better indicator for a high correlation between the common precipitation running variance and ENSO running variance (Fig. 3a) as compared to the case with simulated precipitation data sourced from only one location. For instance, if we select a common precipitation time series, sourced from two geographic locations, that has an $r^{2}$ of between 0.6 and 0.7 with ENSO, there is only a $1 \%$ chance that the common precipitation running variance will have an $r^{2}<0.1(r<0.31)$ when compared with ENSO running variance (Fig. 3a). This is 10 times less likely than the case with simulated precipitation data sourced from only one location. This result is consistent with CCSM4 data, which suggest that a common precipitation time series, sourced from two geographic locations, that has an $r^{2}$ of $>0.7$ when compared to ENSO SSTA 

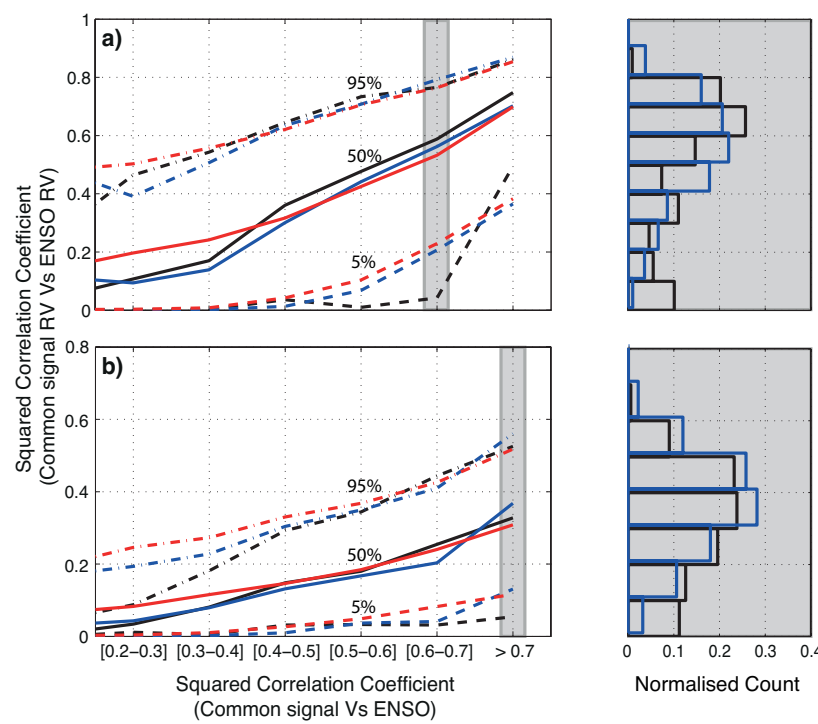

Fig. 3. (a) displays the $5 \%$ (dashed lines), $50 \%$ (solid lines) and $95 \%$ (dash-dot lines) of squared correlation coefficients calculated between CM2.1 simulated precipitation running variance (calculated in a $30 \mathrm{yr}$ sliding window) and ENSO running variance, binned on the $x$ axis against the squared correlation between the simulated precipitation and ENSO. The color of the lines indicates the number of source locations utilized in the precipitation signal, with black, blue and red lines corresponding to one, two and five source locations. The inset histogram displays the distribution of squared correlation coefficients calculated between precipitation running variance and ENSO running variance from the $x$ axis bin of the main plot shaded grey. (b) as in (a) but for CCSM4 model output. Note the different $y$ axis for panels (a) and (b).

will make it 3.5 times less likely that the common precipitation running variance will have an $r^{2}<0.1(r<0.31)$ when compared with ENSO running variance (Fig. 3b).

Thus, these results suggest the following: (i) a strong correlation between $T_{\mathrm{S}}$ and ENSO provides a clear indication that the running variance of $T_{\mathrm{S}}$ is likely to track that of ENSO; (ii) a strong correlation between precipitation and ENSO at a particular location does not guarantee a strong correlation between the running variance of precipitation and the running variance of ENSO. As such, ENSO variance estimates provided by reconstructions derived from precipitation sensitive proxies at a single site should be viewed with caution; and (iii) a multi-site common precipitation signal which is strongly correlated with ENSO provides much better indication that the common precipitation signal's running variance will be related to the running variance of ENSO.

\subsection{Identifying the common variance signal}

A previous study has shown that a linear combination of many of the above-listed individual eastern equatorial Pacific reconstructions can further increase the signal-to-noise ratio compared with the individual reconstructions (McGregor et al., 2010). However, it was noted that the variance changes of this combined proxy product appeared to show the effects of dating errors towards the beginning of the $350 \mathrm{yr}$ record. Similar dating errors have also been noted in studies that attempt to reconstruct observed ENSO over the last $1000 \mathrm{yr}$ (EmileGeay et al., 2013a, b). This is a concern because proxies displaying small dating errors can act to cancel out the common signal when combined - hence artificially reducing the combined signal variance.

\subsubsection{Methods for identifying the common variance signal}

McGregor et al. (2010) proposed that working with the running variance proxy time series should provide a more robust estimate of ENSO's variance changes in the presence of small dating errors than working with raw proxy time series. This is because small dating errors in proxies can act to cancel out the common signal in the $2-8$ yr variability range when combined, acting to artificially reduce the combined signal variance, while the positive definiteness of the running variances precludes this signal cancellation. This is further tested by examining whether identifying the median of the running variance signals (MRV) of numerous source proxies (e.g., median $\left(\sigma^{2}\left(P_{x}(t)\right)\right)$ ) is equivalent to identifying the running variance of the median signal (RVM) (e.g., $\sigma^{2}$ (median $\left.\left(P_{x}(t)\right)\right)$ in the absence of dating errors. The source proxy time series are abbreviated as $P_{x}(t)$. Thus, MRV refers to calculating the running variance for each individual proxy, and then finding the inter-proxy median; whereas RVM refers to the finding the inter-proxy median of the individual time series first, and then calculating the running variance of that common signal.

To assess the performance of these two methods in the absence of dating errors, we analyze the output of the CCSM4 and CM2.1 multi-century model simulations. To this end, we select $x(x=1,2,3, \ldots, 14)$ time series of either precipitation or $T_{\mathrm{S}}$ from random global locations, with the only constraint on the location being that its time series must have a absolute correlation coefficient $>0.3$ when compared to the simulated ENSO (again note that ENSO is represented as area-averaged $T_{\mathrm{S}}$ in the Niño 3.4 region). We then calculate the MRV and $\mathrm{RVM}$ of the $x$ time series. The running variance is calculated in a $30 \mathrm{yr}$ sliding window. This procedure is repeated until we obtain $10000 \mathrm{MRVs}$ and $10000 \mathrm{RVMs}$ for each $x$ representing either precipitation or surface temperature.

Plotting the 5th, 50th and 95th percentiles of the correlation coefficients calculated between ENSO running variance and the MRV as a function of $x$, along with the corresponding 
Table 2. Correlation coefficients calculated between the high-pass-filtered (HPF; $10 \mathrm{yr}$ cutoff) annual mean proxy-network-based ENSO reconstructions and HPF observed ENSO during the overlapping instrumental period, along with the across observational product average displayed in bold font. All correlations are statistically significant above the $99 \%$ level. We note that this measure of statistical significance takes into account serial (auto-)correlation in the series, based on the reduced effective number of degrees of freedom outlined by Davis (1976).

\begin{tabular}{|c|c|c|c|c|c|c|}
\hline \multirow[b]{2}{*}{ No. } & \multirow[b]{2}{*}{ Label } & \multicolumn{5}{|c|}{ Observed ENSO (Niño 3.4 region SSTA) } \\
\hline & & $\begin{array}{r}\text { HadISST } \\
\text { (Rayner et al., 2003) }\end{array}$ & $\begin{array}{r}\text { ERSST V3 } \\
\text { (Smith et al., 2008) }\end{array}$ & $\begin{array}{r}\text { Kaplan } \\
\text { (Kaplan et al., 1998) }\end{array}$ & $\begin{array}{r}\text { Niño } 3.4 \text { SSTA } \\
\text { (Bunge and Clarke, 2009) }\end{array}$ & Average \\
\hline 1 & STAH98t & 0.74 & 0.75 & 0.76 & 0.73 & 0.75 \\
\hline 2 & COOK00t & 0.78 & 0.71 & 0.77 & 0.77 & 0.76 \\
\hline 3 & MANN00m & 0.77 & 0.76 & 0.75 & 0.76 & 0.76 \\
\hline 4 & EVAN01t & 0.54 & 0.69 & 0.55 & 0.59 & 0.59 \\
\hline 5 & EVAN02c & 0.74 & 0.78 & 0.72 & 0.71 & 0.74 \\
\hline 6 & COBB03c & 0.71 & 0.7 & 0.72 & 0.69 & 0.71 \\
\hline 7 & COOK08t & 0.76 & 0.74 & 0.75 & 0.73 & 0.75 \\
\hline 8 & BRAG09t & 0.63 & 0.58 & 0.59 & 0.64 & 0.61 \\
\hline 9 & BRAG09m & 0.69 & 0.66 & 0.66 & 0.69 & 0.68 \\
\hline 10 & MCGR10m & 0.83 & 0.83 & 0.82 & 0.82 & 0.83 \\
\hline 11 & WILS10cE & 0.58 & 0.65 & 0.56 & 0.62 & 0.60 \\
\hline 12 & WILS10c & 0.58 & 0.59 & 0.6 & 0.61 & 0.60 \\
\hline 13 & LI11t & 0.53 & 0.48 & 0.55 & 0.54 & 0.53 \\
\hline 14 & WOLF11 & 0.54 & 0.57 & 0.54 & 0.58 & 0.56 \\
\hline
\end{tabular}

values calculated between ENSO running variance and the RVM, reveals that the percentiles of the two derivation methods are very similar for both fields in both models (Fig. 4). This is also basically confirmed by plotting the ENSO running variance and RVM correlation coefficients against the corresponding ENSO running variance and MRV correlation coefficients (Fig. 5a and c). What is also apparent from both of these panels, however, is that as the number of proxy locations $x$ increases, the RVM outperforms the MRV for low correlation values $(r<0.5)$. For larger correlations though, the mean RVM/MRV correlations follow a one-to-one line reasonably well. The scatter seen in Fig. 5a and c indicates that both methods will provide somewhat different estimates of the ENSO running variance time series; however, in the absence of dating errors the MRV method is statistically comparable to the results of the RVM calculation.

Furthermore, we see that as the number of proxies $(x)$ increases, the common signal is more likely to provide a skillful estimate of ENSO running variance. This confirms one of the initial assumptions used in many paleo-climate studies: that a network of proxies helps to reduce the effects of biases, noise, and weaknesses in the individual indicators (Mann et al., 2000).

\subsubsection{Effects of dating errors on the common running variance signal}

Here we examine whether calculating the MRV (calculating the running variance for each individual proxy, and then finding the inter-proxy median), as opposed to calculating the RVM (finding the inter-proxy median of the individual time series first, and then calculating the running variance of that common signal), alters the effects of dating uncertainties in the reconstructions of ENSO variance. As discussed above, McGregor et al. (2010) proposed that working directly with the running variance time series, as opposed to the raw time series, acts to reduce the effects of dating uncertainties by not allowing slightly shifted signals to damp out the common signal variance. To this end, five sets of precipitation time series are extracted from the CM2.1 simulation, which include all precipitation time series that have the absolute value of the correlation coefficients $>0.3$ with simulated ENSO. In four of these five sets, a fraction of the entire time series is randomly shifted temporally by $1-5 \mathrm{yr}$ to mimic a dating error. What varies between these four sets, however, is the proportion of the time series that is subject to the introduced dating error, changing from $1 / 5,1 / 4,1 / 3$, and $1 / 2$. Thus, of these four precipitation data sets the first has dating errors of between 1 and $5 \mathrm{yr}$ introduced into $1 / 5$ of all time series, the second has dating errors introduced into $1 / 4$ of all time series, and so on.

Using these data and the approach outlined above in Sect. 3.2.1, we select $x(x=1,2,3, \ldots, 14)$ precipitation time series from one of these data sets and then calculate the MRV and RVM. The 5th, 50th and 95th percentiles of the correlations calculated between ENSO running variance and the MRV for each of the five data sets as a function of $x$ reveal that the introduced dating errors have virtually no effect on the estimates of ENSO's running variance time series identified by the MRV method (Fig. 6a). On the other hand, plotting the same percentiles for the correlations calculated 


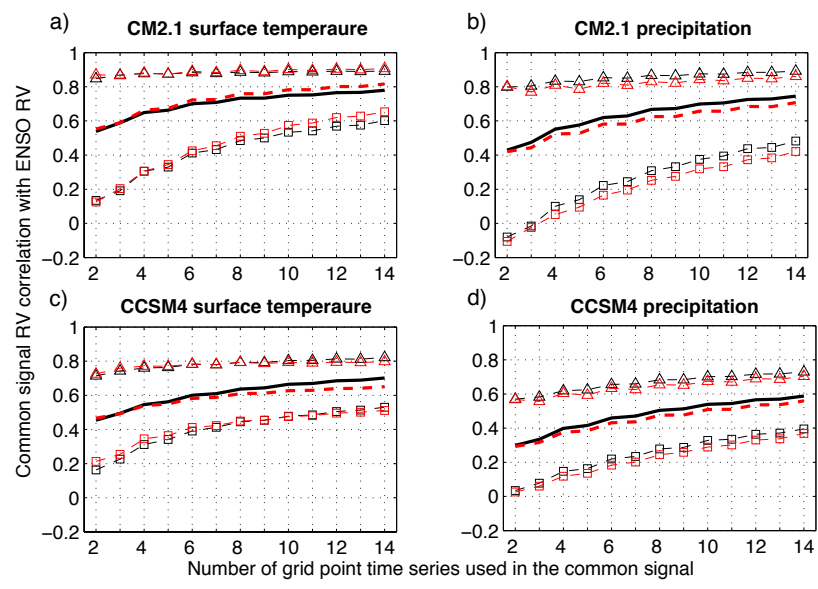

Fig. 4. (a) The $5 \%$ (dashed line with squares), $50 \%$ (solid line) and $95 \%$ (dashed lines with triangles) of the correlation coefficients calculated between the CM2.1 simulated MRV $T_{\mathrm{S}}$ and ENSO running variance are displayed in red, while those of the CM2.1 simulated RVM $T_{\mathrm{S}}$ and ENSO running variance are displayed in black. (b) as in (a) but for the CM2.1 precipitation data. (c) and (d) as in (a) and (b) but for CCSM4 $T_{\mathrm{S}}$ and precipitation data, respectively. The $x$ axis in each panel displays the number of grid point time series used to calculate the common signal.

between ENSO running variance and the RVM signal reveals that the introduced dating errors have a large effect on the estimates of running variance identified by the RVM method (Fig. 6b). This is further illustrated by plotting ENSO running variance and the RVM against the corresponding ENSO running variance and MRV correlation coefficients, both with dating errors introduced in $1 / 2$ of all time series incorporated in the median signals, and comparing this with corresponding values with no introduced dating errors (Fig. 5b and d). The results clearly indicate that the MRV method provides a much more robust estimate of ENSO's running variance than the RVM method when dating errors are present in the input time series. We note that this result remains consistent regardless of the model (CM2.1 or CCSM4) or the output field used (i.e., precipitation or $T_{\mathrm{S}}$ ).

\section{Application to existing ENSO proxy reconstructions}

Here we examine the MRV (calculating the running variance for each individual proxy, and then finding the inter-proxy median) of the 14 existing ENSO reconstructions listed in Table 1 and presented in Fig. $1^{1}$. Each of these reconstructions is based on current and paleo-proxy data sources from a range of geographic regions, with a variety of statistical

\footnotetext{
${ }^{1}$ The term "existing ENSO reconstructions" refers to ENSO reconstructions (see Table 1) that have been previously defined in the scientific literature. These reconstructions often use proxy data from multiple locations and rely on statistical methods to extract the ENSO signal.
}
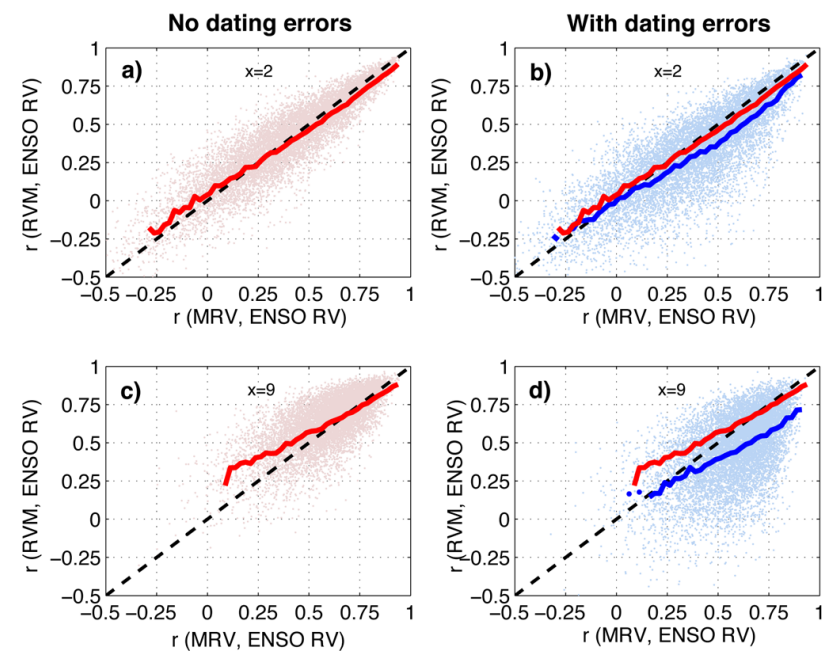

Fig. 5. (a) The correlation between CM2.1 rainfall MRV and ENSO (defined as the area-averaged SSTA in the Niño 3.4 region) running variance plotted against the correlation between CM2.1 rainfall RVM and ENSO running variance for the case with only two members $(x=2)$. Panel (c) displays the same fields, however in this case $x=9$. The solid red line in both of these panels represents the mean correlation of the $r$ (RVM,ENSO RV) in bins of width 0.025 along the $x$ axis. (b) and (d) as in (a) and (c) but $1 / 2$ of all rainfall time series include an introduced temporal shift to mimic a proxy dating error. In both of these panels the solid blue line represents the mean correlation of the $r$ (RVM,ENSO RV) calculated in bins with width 0.025 , while the solid red lines in panels (b) and (d) are mean RVM value from panels (a) and (c), respectively (i.e., those with the same $x$ and no introduced dating error). Note, the black dashed line in all panels represents the one-to-one line, while the mean values are only plotted when the bin contains a minimum of 20 RVM values.

methods used in the derivation of the relevant indices (see Table 1 and references therein). Considering that we have shown that the multi-proxy approach minimizes the impact of weaknesses in any individual proxy (Sect. 3.2.1), it is expected that the use of this wide network of ENSO proxies will allow us to reconstruct the long-term changes in past ENSO variance with greater statistical skill than available from individual reconstructions alone.

Here, as in the model analysis, we focus on the variability in the classical ENSO band of 2-8 yr by filtering each of the 14 ENSO reconstructions with a $10 \mathrm{yr}$ high-pass Butterworth filter. Each of these filtered time series are then normalized using the base period 1900-1977 for the calculation of standard deviation, and a time series running variance is calculated for each reconstruction. Note, as in Sect. 3, running variance is calculated in a $30 \mathrm{yr}$ sliding window. The running variance time series are then adjusted by adding a constant, such that their mean running variance over the period 1900-1977 matches that of the observed ENSO over the same period using instrumental data (Kaplan et al., 1998; Rayner et al., 2003; Smith et al., 2008; Bunge and Clark, 


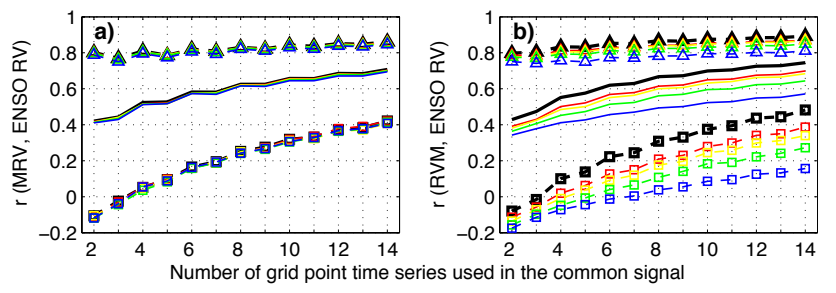

Fig. 6. (a) The $5 \%$ (dashed line with squares), $50 \%$ (solid line) and $95 \%$ (dashed lines with triangles) of the correlation coefficients calculated between the CM2.1 rainfall MRV and ENSO running variance, while (b) displays the percentiles of correlation coefficients calculated between CM2.1 rainfall RVM and ENSO running variance. The black lines indicate those percentiles using data with no introduced dating errors, while the red, yellow, green and blue line respectively represent those percentiles using data with $1 / 5,1 / 4,1 / 3$, $1 / 2$ of the time series including an introduced dating error.

2009). As in the models, the observed ENSO is represented as area-averaged temperature in the Niño 3.4 region and for consistency with the reconstructions it has been filtered with a $10 \mathrm{yr}$ high-pass Butterworth filter. The large spread between the running variances, shown in Fig. 1, highlights the discrepancies amongst the ENSO reconstruction variances (see also grey dots in Fig. 7).

Comparing the MRV of the ENSO reconstructions with the MRV of the observed ENSO over the instrumental period reveals a remarkable correspondence (Fig. 7). The swing from high variance in the earliest decades of the 20th century to low variance in the middle of the 20th century and an increasing trend thereafter are well reproduced in the reconstruction MRV. Note that the MRV of the observed ENSO is calculated across 4 available observational estimates (Table 2). The correspondence between observations and reconstructions further increases the confidence in the MRV technique applied here. Figure 7 also reveals that the amplitude of the observed MRV in the most recent $30 \mathrm{yr}$ of the 20th century (1979-2009, indicated by the red star) appears to have been larger than the variance in any $30 \mathrm{yr}$ window during the preceding multi-century reconstruction MRV record.

We note that the number of ENSO reconstructions taken into account when calculating its MRV signal varies with time, depending on the length and span of the individual records (Fig. 7, Table 1). Error bars are calculated using two separate pseudo-proxy methods, such that the length of the error bar varies in relation to the number of available ENSO proxies (see Appendix A). For instance, with fewer ENSO reconstructions available (e.g., during the period 1400-1500) the running variance estimate becomes more uncertain than for a period (e.g., the 1800s) where many more ENSO reconstructions are available. At any point in time the most conservative (widest) error bar of the two pseudo proxy methods (Appendix A) is displayed in Fig. 7.

The increased variance of observed ENSO for the most recent $30 \mathrm{yr}$ is significantly larger (exceeding the $95 \%$ confidence level) than for any $30 \mathrm{yr}$ interval during the period 1590-1880 (i.e., the observed variance, indicated by the red star, is larger than the ENSO reconstruction MRV error bars in the period from the year 1590 through to the start of the instrumental data). Prior to 1590, however, the uncertainty range of the MRV signal, estimated by the error bars, is too large to be conclusive.

\subsection{Independence of existing ENSO proxy reconstructions}

We note that some of the input proxy networks overlap among these 14 ENSO reconstructions (see Appendix B for a more in-depth discussion), such that they are not always completely independent in a geographical sense. In spite of the geographical overlap for some of the reconstructions, usually different statistical methods are applied to tease out the ENSO signal. These methods range from calculating an empirical orthogonal function (EOF) of the input proxy network (e.g., Braganza et al., 2009; McGregor et al., 2010; $\mathrm{Li}$ et al., 2011) to the more complex method of regressing proxy data onto the leading spatio-temporal eigenmodes of observed data (e.g., Mann et al., 2000; Evans et al., 2002; Cook et al., 2008).

Despite the methodological differences, this lack of independence raises the concern that the noise, i.e., the non-ENSO component of these overlapping input proxies, may distort or mask the common ENSO signal and this could be incorrectly attributed to changes in ENSO. If this were true, we would expect the noise influencing tropical coral-dependent reconstructions to be distinct from that of North American tree rings. As such, if the running variance of either or both of these groups' reconstructions were dominated by noise, we would expect to see significant differences in their common variance signal. However, this is not the case. Identifying the common variance signal in only those reconstructions with common tropical corals reveals a post-1700 signal that is extremely similar to that identified in only those reconstructions with common North American tree rings (Fig. 8). In addition, both of the above signals resemble the MRV identified from the full set of ENSO reconstructions. This gives us confidence that the MRV identified in this study is not strongly distorted or dominated by ENSOindependent noise. We note that reconstructions 3 and 9 include common tropical corals and North American tree rings; however, neglecting these two reconstructions from both of the above subsets leaves the common variance signals virtually unchanged (figure not shown).

\section{Application to observed single-station proxies}

It is also noted here that by using existing ENSO reconstructions that exhibit high correlations with observed ENSO during the instrumental period, we have attempted to consolidate 


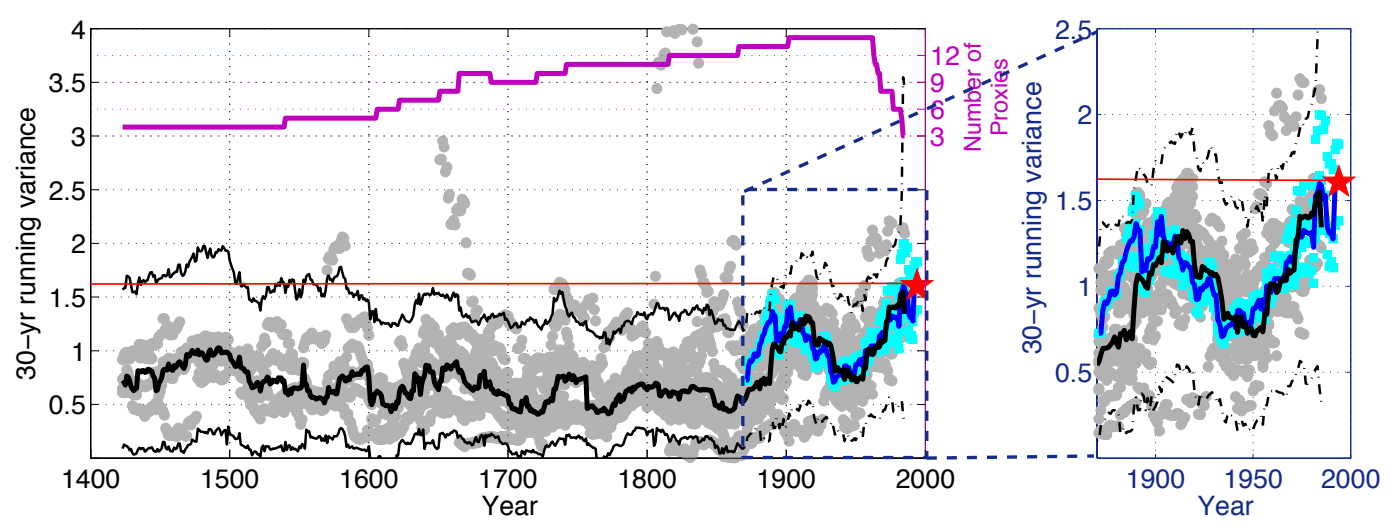

Fig. 7. The running variance (grey dots) of each of the 14 ENSO reconstructions, overlaid with the MRV (thick black line). At any point in time prior to the observation period, the thin black lines represent the widest median running variance signal error bars of the two types of error analysis detailed in Appendix A. Inside the window of instrumental data these error bars change to thin black dash-dot lines, as we have a direct measurement of ENSO variance. The width of each of these two error bar estimates varies depending on the number of ENSO variance proxies available (see purple line at top of panel). Cyan dots indicate the running variance of 4 different estimates of observed ENSO (Table 2), while the blue line represents the MRV of these observed ENSO running variance time series. The red star indicates the most recent value of the observed MRV, while the thin red line just extends this most recent value back through time, for comparison with the ENSO reconstruction MRV and its error bars.

the common information contained within these reconstructions rather than defining another reconstruction to add to the literature. However, as the ENSO reconstructions in most cases have already incorporated information from numerous time series, artificial variance reduction due to dating errors in the source proxies may already be incorporated into our analysis. As such, we may not be getting the best out of the methodological advantage of combining running variances when applying it to these synthesized time series.

Thus, here we also examine the MRV signal in a range of single-location proxies from either within or surrounding the Pacific Basin and compare the results with those derived above (Table 3). Again we focus on the interannual ENSO frequency by filtering each of the proxy time series with a $10 \mathrm{yr}$ high-pass Butterworth filter. We utilize all tree ring proxies listed by Emile-Geay et al. (2013a, b) and all tropical Pacific coral proxies available from the NOAA National Climate Data Center (NCDC) that continuously span the period 1800-1980. Use of this time period ensures that all included proxies provide at least $50 \mathrm{yr}$ of information prior to the start of observed estimates of SST, which start between 1854 and 1886. However, prior to their inclusion in Table 3, these proxies were pre-screened to ensure they have a correlation of at least 0.3 when compared with observed ENSO (Table 4). Each of these filtered proxy time series are then normalized over the 1900-1977 period, and a time series of running variances, in a thirty-year sliding window, is calculated for each reconstruction. The variance time series are then adjusted by adding a constant, such that their mean running variance over the period 1900-1977 matches that of observed ENSO over the same period.

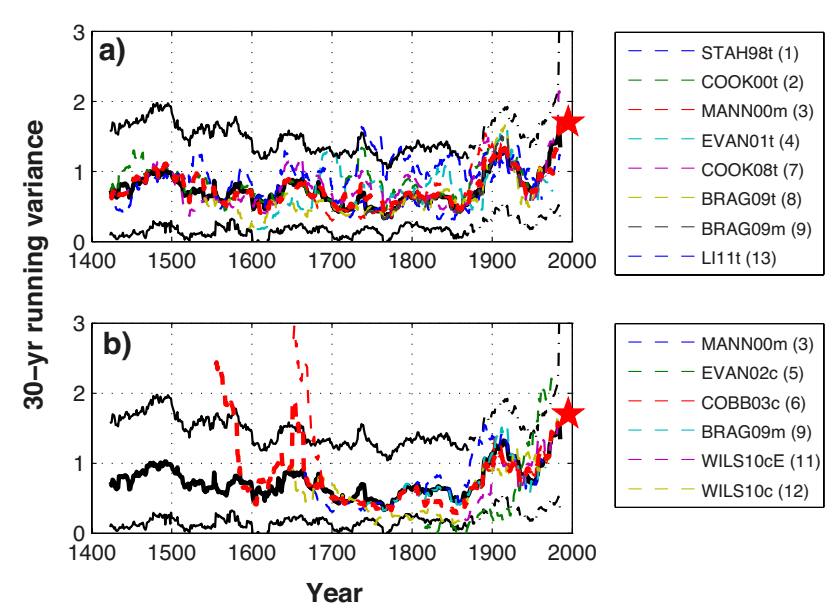

Fig. 8. (a) The running variance of each of the 8 ENSO reconstructions with common tree ring source proxies (proxy names and numbers correspond to those in Table 1), overlaid with the corresponding MRV (thick dashed red line). (b) The running variance of each of the 6 ENSO reconstructions with common tropical coral reconstructions (proxy numbers in legend correspond to those in Table 1), overlaid with the corresponding MRV (thick dashed red line). The underlying thick black line in both panels represents the MRV of all 14 ENSO reconstructions presented in Fig. 7 and Table 1, while the thin black lines represent the accompanying ENSO reconstruction MRV signal error bars (Appendix A). The red star indicates the most recent value of the observed MRV (see Fig. 7).

Calculating the MRV signal of all proxies listed in Table 3 reveals a time series that displays a good correspondence to the MRV of the observed ENSO (Fig. 9a inset). This single-station proxy MRV time series falls well within the error estimates of the ENSO reconstruction MRV time 
Table 3. The single station (SS) temperature and/or rainfall proxies employed in this study. Note that these proxies have at least annual resolution and are pre-screened such that they have a correlation of at least 0.3 with the annual mean (July-June) observations of ENSO, represented by Niño 3.4 area-averaged (hereafter N34, $5^{\circ} \mathrm{S}-5^{\circ} \mathrm{N}, 120^{\circ} \mathrm{W}-170^{\circ} \mathrm{W}$ ) SST anomalies (Table 4). This correlation cutoff ensures that the proxies provide a reasonably skillful estimate of ENSO variability over the instrumental epoch.

\begin{tabular}{|c|c|c|c|c|c|c|c|}
\hline & Reference & Period & Proxy type & Location & Source region & Lat & Lon \\
\hline SS proxy 1 & Cook et al. (2008) & $0-2006$ & Tree ring width & NADA PDSI & North America & $27^{\circ} \mathrm{N}$ & $255^{\circ} \mathrm{E}$ \\
\hline SS proxy 2 & Le Quesne et al. (2006) & $1000-2000$ & Tree ring width & Chilean Cordillera & South America & $33^{\circ} \mathrm{S}$ & $288^{\circ} \mathrm{E}$ \\
\hline SS proxy 3 & ITRDB extraction & $1675-1998$ & Tree ring width & Madera Canyon & Mexico & $29^{\circ} \mathrm{N}$ & $257^{\circ} \mathrm{E}$ \\
\hline SS proxy 4 & ITRDB extraction & 1553-1998 & Tree ring width & Nevado de Colima & Mexico & $20^{\circ} \mathrm{N}$ & $256^{\circ} \mathrm{E}$ \\
\hline SS proxy 5 & ITRDB extraction & 1376-1998 & Tree ring width & Cerro Baraja & Mexico & $26^{\circ} \mathrm{N}$ & $254^{\circ} \mathrm{E}$ \\
\hline SS proxy 6 & ITRDB extraction & 1376-1999 & Tree ring width & Cerro Baraja & Mexico & $26^{\circ} \mathrm{N}$ & $254^{\circ} \mathrm{E}$ \\
\hline SS proxy 7 & ITRDB extraction & 1644-1998 & Tree ring width & Creel Int. Airport & Mexico & $28^{\circ} \mathrm{N}$ & $252^{\circ} \mathrm{E}$ \\
\hline SS proxy 8 & ITRDB extraction & 1481-1998 & Tree ring width & El Salto & Mexico & $24^{\circ} \mathrm{N}$ & $254^{\circ} \mathrm{E}$ \\
\hline SS proxy 9 & ITRDB extraction & 1583-1998 & Tree ring width & El Tabacote/Tomochic & Mexico & $28^{\circ} \mathrm{N}$ & $252^{\circ} \mathrm{E}$ \\
\hline SS proxy 10 & ITRDB extraction & $1712-1998$ & Tree ring width & Capote Knob & Texas, USA & $29^{\circ} \mathrm{N}$ & $262^{\circ} \mathrm{E}$ \\
\hline SS proxy 11 & ITRDB extraction & 1473-1998 & Tree ring width & Camp Spring & Texas, USA & $29^{\circ} \mathrm{N}$ & $257^{\circ} \mathrm{E}$ \\
\hline SS proxy 12 & ITRDB extraction & 1473-1998 & Tree ring width & Camp Spring & Texas, USA & $29^{\circ} \mathrm{N}$ & $257^{\circ} \mathrm{E}$ \\
\hline SS proxy 13 & Asami et al. (2005) & $1790-2000$ & Coral $\left(\delta^{18} \mathrm{O}\right)$ & Double Reef & Guam & $13^{\circ} \mathrm{N}$ & $144^{\circ} \mathrm{E}$ \\
\hline SS proxy 14 & Bagnato et al. (2005) & $1776-2001$ & Coral $\left(\delta^{18} \mathrm{O}\right)$ & Savusavu Bay & Fiji & $16^{\circ} \mathrm{S}$ & $179^{\circ} \mathrm{E}$ \\
\hline SS proxy 15 & DeLong et al. (2012) & $1648-2000$ & Coral $(\mathrm{Sr} / \mathrm{Ca})$ & Amédée Island & New Caledonia & $22^{\circ} \mathrm{S}$ & $166^{\circ} \mathrm{E}$ \\
\hline SS proxy 16 & Isdale et al. (1998) & 1644-1986 & Coral (Fluorescence) & Havannah Island & Great Barrier Reef & $18^{\circ} \mathrm{S}$ & $146^{\circ} \mathrm{E}$ \\
\hline SS proxy 17 & Isdale et al. (1998) & $1737-1980$ & Coral (Fluorescence) & Pandora Reef & Great Barrier Reef & $18^{\circ} \mathrm{S}$ & $146^{\circ} \mathrm{E}$ \\
\hline SS proxy 18 & Linsley et al. (2000) & 1727-1997 & Coral $(\mathrm{Sr} / \mathrm{Ca})$ & Rarotonga & Cook Islands & $21^{\circ} \mathrm{S}$ & $159^{\circ} \mathrm{W}$ \\
\hline SS proxy 19 & Lough (2007) & $1631-2005$ & Coral (Fluorescence) & Queensland River Flow & Great Barrier Reef & $17-23^{\circ} \mathrm{S}$ & $146-151^{\circ} \mathrm{E}$ \\
\hline SS proxy 20 & Quinn et al. (1998) & 1657-1992 & Coral $\left(\delta^{18} \mathrm{O}\right)$ & Amédée Island & New Caledonia & $22^{\circ} \mathrm{S}$ & $166^{\circ} \mathrm{E}$ \\
\hline SS proxy 21 & Charles et al. (2003) & $1782-1990$ & Coral $\left(\delta^{18} \mathrm{O}\right)$ & Lombok Straight & Indonesia & $8^{\circ} \mathrm{S}$ & $115^{\circ} \mathrm{E}$ \\
\hline
\end{tabular}

Table 4. Correlation coefficients with zero lag, and lead and lag times of one year $(t-1$ means proxy data lagging observed ENSO), calculated between the high pass filtered (HPF; $10 \mathrm{yr}$ cutoff) annual mean single station proxy network (Table 3) and the annual mean (JulyJune) observations of ENSO, represented by Niño 3.4 area-averaged $\left(5^{\circ} \mathrm{S}-5^{\circ} \mathrm{N}, 120^{\circ} \mathrm{W}-170^{\circ} \mathrm{W}\right) \mathrm{SST}$ anomalies during the overlapping instrumental period. The maximum correlation for each observational product is highlighted by bold font.

Observed Niño 3.4 region SSTA

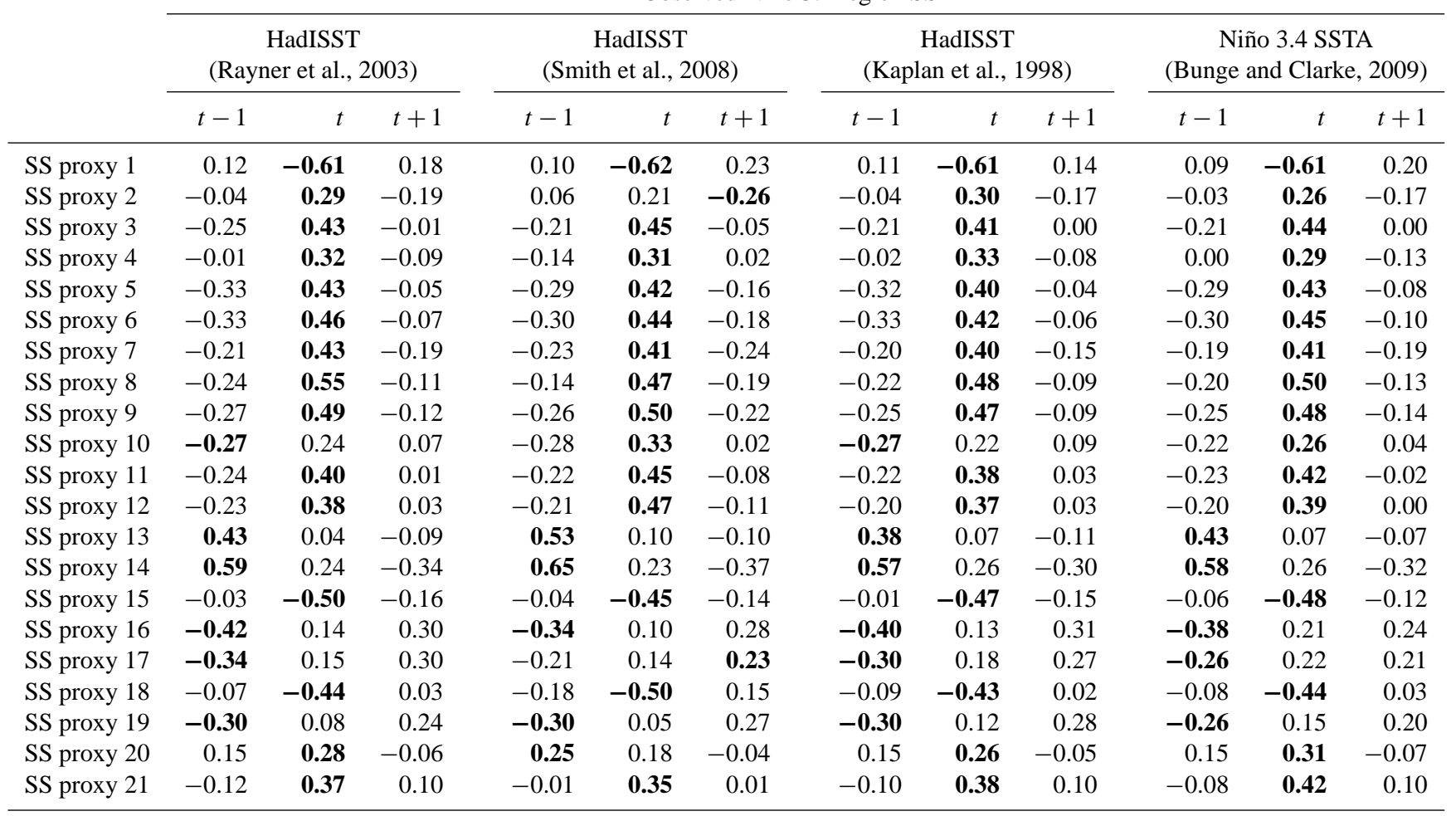



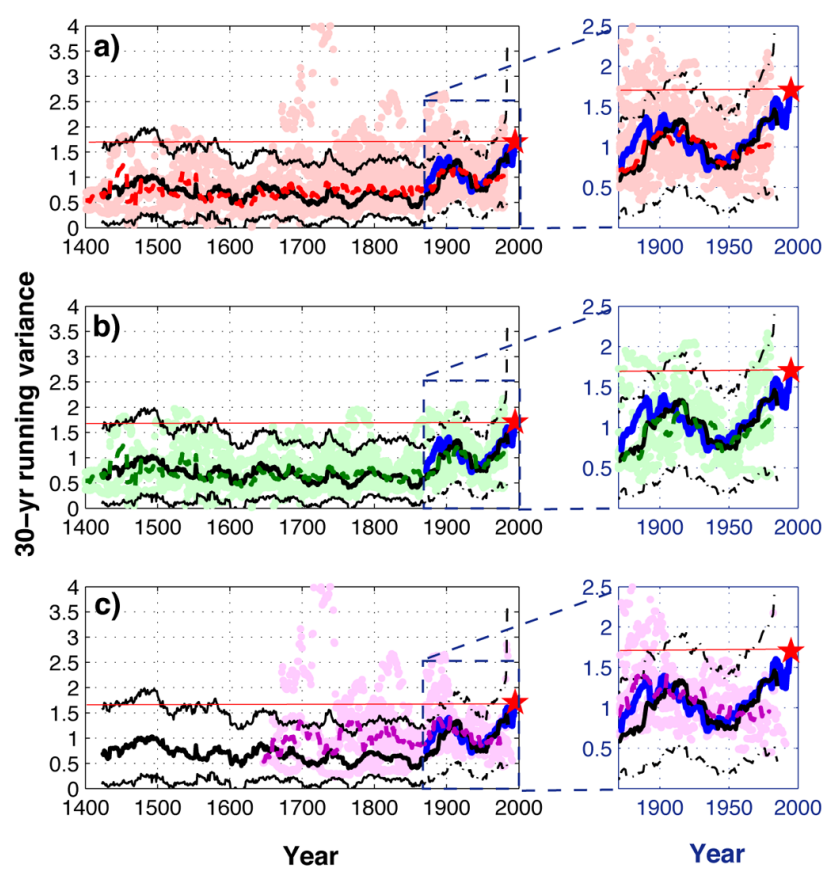

Fig. 9. (a) The running variance (pink dots) of each of the 21 singlestation proxies (Table 3 ) overlaid with their MRV (thick dashed red line). (b) The running variance of the 12 single-station tree ring proxies (light green dots) overlaid with the corresponding MRV (thick green dashed line), while (c) displays the running variance of the 9 single-station coral proxies (light purple dots) overlaid with the corresponding MRV (thick purple dashed line). The thick black line in all three panels represents the MRV of all 14 HPF (10 yr cutoff) ENSO reconstructions presented in Fig. 7 and Table 1, while the thin black lines represent the accompanying ENSO reconstruction MRV signal error bars (Appendix A). As in Fig. 7, the blue line represents the MRV of observed ENSO and the red star indicates its most recent value, while the thin red line just extends this most recent value back through time for comparison with the proxy MRV signals.

series presented in Sect. 4.1 and Fig. 7. In fact, comparing the single-station proxy MRV time series with that of the MRV ENSO reconstruction reveals a strong similarity through most of the $600 \mathrm{yr}$ period (Fig. 9a).

Using only the 12 single-station tree ring proxies (sourced from Emile-Geay et al., 2013; Table 3) we calculate the MRV signal. Comparing this single-station tree ring MRV signal with the MRV of the observed ENSO reveals a good correspondence (Fig. $9 \mathrm{~b}$ inset). Again, this single-station MRV time series falls well within the error estimates of the ENSO reconstruction MRV time series, and directly comparing this single-station MRV time series with that of the ENSO reconstruction MRV time series reveals a strong similarity through most of the $600 \mathrm{yr}$ period (Fig. 9b).

Calculating the MRV signal of the 9 coral proxies from Table 3, and comparing this with the MRV of the observed ENSO, reveals some correspondence (Fig. 9c inset), although the correlation appears much weaker than for the single-station tree ring MRV (Fig. 9b inset). The correspondence is most notable prior to 1960; after this time the MRV of observed ENSO begins to steadily increase while the single-station coral proxy MRV signal remains relatively constant. The facts that (i) the single-station coral proxy MRV does not pick up the increase in ENSO variance since the mid-1900s, and that (ii) there is very little correspondence between the single-station coral proxy MRV and the ENSO reconstruction MRV time series outside of the period 18501950 (Fig. 9c), reduces our confidence in this signal, which is namely sourced from the southwestern tropical Pacific, as it relates to ENSO. As the southwestern tropical Pacific is home to the South Pacific Convergence Zone (SPCZ), a possible explanation for these discrepancies could be that there may have been slow shifts in the tropical Pacific temperature/rainfall covariance that could have affected some of the $\delta^{18} \mathrm{O}$-based coral proxies in this region. However, in spite of this, the coral common variance time series falls mostly within the error estimates of the ENSO proxy reconstruction MRV signal.

Thus, consistent with the analysis of existing ENSO reconstructions presented in Fig. 7, the MRV of the single-station proxies of Table 3 (whether they are based on all singlestation proxies or solely on coral or tree ring single-station proxies) reveals that the observed variance of ENSO in the most recent $30 \mathrm{yr}$ of the 20th century (indicated by the red star) appears to have been larger than at any time during the preceding multi-century record.

\section{Discussion and conclusions}

The main goal of this study was to synthesize existing ENSO reconstructions to arrive at a better estimate of past ENSO variance changes. This is an important task since there are considerable discrepancies in ENSO variance estimates derived from the 14 available ENSO reconstructions that exhibit good correlations with the instrumental data (Figs. 1 and 7 and Table 2). Throughout the manuscript variance changes in the $10 \mathrm{yr}$ high-pass-filtered ENSO reconstructions were calculated in a $30 \mathrm{yr}$ sliding window to capture multi-decadal variance changes. Sensitivity analysis suggests that the results discussed here are not sensitive to the high-pass filtering or the running variance window length (not shown).

We first tested an implicit assumption of many ENSO reconstruction studies, namely, that if a temperature or precipitation-sensitive proxy represents ENSO variability well, it will also represent ENSO running variance well. Our results from the analysis of two independent multi-century CGCM simulations suggest that this assumption is valid for proxies of temperature variability, but not for single proxies of precipitation variability. That is, while local precipitation may be modulated by ENSO, its running variance might bear a much weaker correlation with ENSO's running variance. 
Thus, we recommend caution when inferring ENSO running variance from precipitation-sensitive proxy data from a geographically confined area, even if the data originate from ENSO's main activity region in the central/eastern equatorial Pacific. Furthermore, we demonstrated that this effect is significantly reduced when a common precipitation signal is sourced from a range of geographic regions. That is, a common precipitation signal, which is strongly correlated with ENSO, provides a much better indication that the correlation between the rainfall running variance and ENSO running variance will also be strong.

By focusing on the median of the running variances of individual source signals in this study we considerably simplified the approach of McGregor et al. (2010), who utilized a principle component analysis (PCA) of running variance time series. Our new method has two main advantages: (i) it can easily deal with discontinuous data, and (ii) it does not weight the contribution of individual proxies on the combined signal, which may make it less sensitive to changes in ENSO's teleconnections over time.

Our model analysis then showed that in the absence of dating errors, the MRV method (median running variance, i.e., calculating the running variance for each individual proxy, and then finding the inter-proxy median) yields similar results to the RVM (running variance of the median, i.e., finding the inter-proxy median of the individual time series first, and then calculating the running variance of that common signal) approach. However, MRV is much less sensitive to dating errors than RVM. This is because small dating errors in the proxy time series can act to cancel out the common signal when combined, acting to artificially reduce the combined signal variance; the positive definiteness of running variances prevents this signal cancellation.

The results of our model analysis also show that as the diversity of input proxies increases, the resulting common variance signal is more likely to provide a skillful estimate of ENSO running variance. This confirms one of the initial assumptions used in many paleo-climate studies: that a broad network of proxies helps to reduce the effects of biases and weaknesses in the individual indicators (Mann et al., 2000). Thus, we expect the MRV method to increase the signal-tonoise ratio of the ENSO variance changes, while minimizing the effects of dating uncertainties in the source proxies.

As such, we applied this method to synthesize the variance information contained in 14 preselected ENSO reconstructions (Table 1), and in 21 single-station proxy records (Table 3). However, prior to summarizing the key results of this analysis, we discuss several important limitations of the modeling and proxy analyses presented in this study.

The model analysis presented in Sect. 3 includes several caveats. First, model biases in the mean state and ENSO teleconnections could produce biases in the spatial patterns of difference between anomaly and running variance correlations with ENSO. Second, mixed temperature and rainfall sensitivities of some proxies (e.g., Cobb et al., 2003) could complicate the interpretation in Sect. 3.1; however, for realworld applications perhaps the most conservative interpretation of these results is that a multi-site reconstruction of ENSO variance provides a more robust indication of changes in ENSO signal running variance than single-site proxy reconstructions. Third, ENSO teleconnections might not truly be stationary; however, as we have been assessing our methods against the modeled ENSO variability, at least any simulated changes in teleconnections would be implicitly included in our analysis.

The proxy analyses presented in Sects. 4 and 5 also includes several caveats. First, although our combined variance estimate (Sect. 4) is supported by the running variance signal calculated from uncalibrated single-station corals (see Sect. 5), we do not assess the sensitivity of individual source ENSO reconstructions to their derivation and calibration techniques. A recent study has suggested that reconstructed centennial-scale variability is particularly sensitive to the historical SST data set used during calibration (EmileGeay et al., 2013a, b). Second, we assume that the spatial structure of ENSO SSTA and ENSO's teleconnections do not change over time; this is a concern, as the single-station proxies (Table 3 ) are largely sourced from regions considered teleconnected to ENSO and do not include any proxies from ENSO's center of action in the eastern/central tropical Pacific. While the common running variance signals of these single-station proxies support the synthesis of pre-defined ENSO reconstructions, the differences between the common running variance time series could reflect changes of teleconnection patterns over time (Fig. $9 \mathrm{~b}$ and c).

With these caveats in mind, our synthesis of the 14 predefined ENSO reconstructions (Table 1), along with the analysis of 21 single-station proxy records (Table 3), suggests that the observed variance of ENSO over the period 19792009 was larger than the variance in any $30 \mathrm{yr}$ window from the preceding $600 \mathrm{yr}$. As a result of the larger error bars in the estimates for the period prior to $1590 \mathrm{CE}$, however, we cannot rule out that the levels of ENSO variance that occurred between 1400 and 1590 may be comparable to that of 1979-2009. The unusually high 20th-century ENSO variance is consistent with our previous results (McGregor et al., 2010), with other studies based on multi-site tree ring reconstructions ( $\mathrm{Li}$ et al., 2013) and with the recent coral studies of Hereid et al. (2013) and Cobb et al. (2013).

Within the current methodology, sources of uncertainty could be reduced by (i) increasing the number of ENSO proxy reconstructions representing ENSO variability prior to $1600 \mathrm{CE}$, and/or (ii) increasing the number of annually resolved single-station proxies that represent ENSO variability. The increase in single-station proxies should preferably occur outside of the two regions most commonly used in ENSO reconstructions (Table 3), namely Central/North America (tree rings) and the southwest tropical Pacific (corals). 


\section{Appendix A}

\section{Error bar calculation}

The main goal of this pseudo-proxy technique is to assess how accurately the median of multiple pseudo-proxies can estimate the variance of the original proxies from which the pseudo-proxies are generated. Here we define the original source proxy as the "true" signal. To this end, each of the 14 normalized high-pass-filtered proxy time series $p_{i}(t)(i=1, \ldots, 14)$ (Table 1) is used as a true signal. Pseudo-proxies $p p_{i j}(t)=p_{i}(t)+s z_{j}(t)(j=1, \ldots, J ; J=$ $600)$ are generated by adding Gausian white noise $z_{j}(t)$ to the annual mean true signal. The variance of $z_{j}(t)$ is randomly modulated by $s$, such that the correlation coefficient between the pseudo-proxy $p p_{i j}(t)$ and the original proxy $p_{i}(t)$ (the true signal) is contained within the range of correlation coefficients between the original proxies and the instrumental SSTA signal (see Table 2). By definition, selecting numerous pseudo-proxies and averaging (mean $\left.\left(p p_{i}(t)\right)=J^{-1} z_{j} p p_{i j}(t)\right)$ should allow for the true signal $p_{i}(t)$ to be identified, as the additive Gaussian white noise would cancel out if enough pseudo-proxies were utilized. If none of the proxy records had dating errors, the $30 \mathrm{yr}$ running variance of mean $\left(p p_{i}(t)\right)$ would match that of the "true proxy" $p_{i}(t)$. Unfortunately, the number of ENSO proxies is currently limited to 14 , so averaging cannot completely attenuate the noise. Furthermore, the available proxy data will likely have dating errors leading to an artificial damping of the combined signal variance.

To bypass this signal cancellation issue, the $30 \mathrm{yr}$ running variance of $p p_{i j}(t)$ is calculated, giving $p p_{i j}^{\mathrm{rv}}(t)$. The variance of these $p p_{i j}^{\mathrm{rV}}(t)$ time series is then adjusted by adding a constant, such that their mean running variance over the period 1900-1977 matches that of the true proxy over the same period. The addition of this constant to the running variance time series is equivalent to adding the effects of weather noise, which has variance equivalent to the magnitude of the constant, to the signal. From this point two methods can be used to estimate the error bar for the running variance time series:

1. The first method generates $n=5000$ groups for each proxy (i) that contains $m=3$ randomly selected pseudo-proxy running variance time series $\left(p p_{i j}^{\mathrm{rv}}(t)\right)$, and 5000 groups that contain $m=4$ randomly selected pseudo-proxy running variance time series $\left(p p_{i j}^{\mathrm{rv}}(t)\right)$, etc., with $m$ going up to 14 . Hence the total number of realizations of pseudo-proxy running variances in this ensemble is $14 \times 102 \times 5000$, where $102=\sum_{m=3}^{14} \mathrm{~m}$. The median of this set is then calculated with respect to $m$; e.g., for $m=3,4, \ldots, 14$ and for any given $i$ we obtain the median over these $m$ realizations in each of the 5000 groups $=>m p p_{i m n}^{\mathrm{rv}}(t)$ giving a $14 \times 12 \times 5000$ matrix. Then for each $i$ we calculate the error of these
5000 groups of median running variances with respect to the corresponding true running variance giving $\varepsilon_{i m n}^{\mathrm{rv}}(t)=p_{i}^{\mathrm{rv}}(t)-m p p_{i m n}^{\mathrm{rv}}(t)$. The matrix $\varepsilon_{i m n}^{\mathrm{rv}}(t)$ is also of dimension $14 \times 12 \times 5000$. To obtain an estimate of the uncertainty in running variances that can be applied to the median ENSO proxy variance presented here, and to maintain positive definiteness of the variance range, the following procedure is applied: the true proxy running variance as a function of time $p_{i}^{\mathrm{rv}}(t)$ is split into $p=8$ bins of equal width (going from 0.25 to 2$)$ depending on the value of $p_{i}^{\mathrm{rv}}(t)$; also the $n$ corresponding error estimates $\left(\varepsilon_{i m n}^{\mathrm{rv}}(t)\right)$ are binned into the same 8 equal bins $=>\operatorname{binned-} \varepsilon_{i m p}^{\mathrm{rv}}(q)$ is a $14 \times 12 \times 8 \times p$ matrix where the number of error estimates in each bin $(q)$ is a multiple of $n$. For each bin and each proxy $i$ the 5th and 95th percentiles of the realizations are computed within this bin. For each $i$ and $m$ there are now 8 sets of error bars, which depend on the magnitude of the corresponding true running variance signal. A conservative estimate of the error bars is obtained by taking the minimum or maximum of these 5th and 95th percentiles, respectively, over all $i$. Depending on how many true proxies $m$ are available at time $t(m=3, \ldots, 14)$, the corresponding proxyvariance magnitude-dependent conservative error bars are selected for the corresponding $m$ to get the final proxy variance uncertainty range.

2. The second method simply calculates the median of the $p p_{i j}^{\mathrm{rv}}(t)$ over the $i$ dimension, giving $m p p_{j}^{\mathrm{rv}}(t)$. As the number of original proxy time series at any point in time is consistent with the magenta line in Fig. 3, this calculation directly provides 600 pseudo-estimates of the proxy median time series displayed in Fig. 2a (black line). The error bars calculated via this method implicitly incorporate the number of proxies used to estimate the variance at each time step and the magnitude of the signal it is trying to represent, so error bars are then calculated at each point in time by simply identifying the $5 \%$ and $95 \%$ levels.

As the addition of white noise to the pseudo-proxies acts to increase the mean variance of each pseudo-proxy time series, the shifting of each of the pseudo-proxy running variance time series by adding a constant (such that the mean of the last $100 \mathrm{yr}$ matches that of the true signal $\left.p_{i}^{\mathrm{rv}}(t)\right)$ may act to shift the positive definite pseudo-proxy error bars towards more negative values - hence making it possible that the pseudo-proxy error bars include negative values. Such values will not be considered here, because of the positive definiteness of variances. 


\section{Appendix B}

\section{Proxy data independence}

In Sect. 4, we noted that some of the input proxy networks used to develop these 14 ENSO reconstructions overlap. Neglecting reconstruction 10 , which utilizes reconstructions 19 in its derivation along with the Urvina Bay corals (Dunbar et al., 1994), this input proxy data overlap can be broken down into two main groups, those utilizing North American tree rings and tropical corals:

i. North American tree rings: very similar tree ring networks make up the entire input of two reconstructions (numbers 7 and 13 in Table 1), and a subset (roughly $25 \%$ ) of this network is also used in reconstruction number 2 (E. R. Cook, personal communication, 2009). Various subsets of this tree ring data are also utilized in reconstructions $1,3,4,8$ and 9 .

ii. Tropical corals:

a. Corals from reconstruction number 6 (Table 1) are used in the Wilson et al. (2010) center of action (COA) reconstruction (number 11 in Table 1).

b. Urvina Bay (Dunbar et al., 1994) and Punta Pitt (Shen et al., 1992) corals are utilized in reconstructions 5 and 11.

c. Clipperton Atoll corals (Linsley et al., 2000) are utilized in reconstructions 9 and 11.

d. Seychelles Island (Charles et al., 1997) and Espiritu Santo Island (Quinn et al., 1993) corals are utilized in reconstructions 5 and 12 .

e. The reconstruction of Mann et al. (2000) also uses Urvina Bay (Dunbar et al., 1994) and Espiritu Santo Island (Quinn et al., 1993) corals along with several other corals (e.g., Heiss, 1994; Linsley et al., 1994) that are utilized in the Evans et al. (2002) reconstruction (number 5).

Acknowledgements. S. McGregor and M. H. England were supported by the Australian Research Council grants DE130100663 and FL100100214. A. Timmermann was supported by US NSF grant 1049219 and through the Japan Agency for Marine-Earth Science and Technology (JAMSTEC) through its sponsorship of the International Pacific Research Center (IPRC).

Edited by: J. Luterbacher

\section{References}

Asami, R., Yamada, T., Iryu, Y., Quinn, T. M., Meyer, C. P., and Pauley, G.: Interannual and decadal variability of the western Pacific sea surface condition for the years 1787-2000: Reconstruction based on stable isotope record from a Guam coral, J. Geophys. Res., 110, C05018, doi:10.1029/2004JC002555, 2005.

Bagnato, S., Linsley, B. K., Howe, S. S., Wellington, G. M., and Salinger, J.: Coral oxygen isotope records of interdecadal climate variations in the South Pacific Convergence Zone region, Geochem. Geophy., Geosys., 6, Q06001, doi:10.1029/2004GC000879, 2005.

Braganza, K., Gergis, J. L., Power, S. B., Risbey, J. S., and Fowler, A. M.: A multiproxy index of the El Niño-Southern Oscillation, A.D. 1525-1982, J. Geophys. Res., 114, D05106, doi:10.1029/2008JD010896, 2009.

Bunge, L. and Clarke, A. J.: A verified estimation of the El Niño index NINO3.4 since 1877, J. Climate, 22, 3979-3992, 2009.

Capotondi, A., Wittenberg, A., and Masina, S.: Spatial and temporal structure of tropical Pacific interannual variability in 20th century coupled simulations, Ocean Model., 15, 274-298, doi:10.1016/j.ocemod.2006.02.004, 2006.

Chan, J.: Tropical cyclone activity in the northwest Pacific in relation to the El Niño/Southern Oscillation phenomenon, Mon. Weather Rev., 113, 599-606, 1985.

Charles, C. D., Hunter D. E., and Fairbanks, R. G.: Interaction between the ENSO and the Asian monsoon in a coral record of tropical climate, Science, 277, 925-928, 1997.

Charles, C. D., Cobb, K., Moore, M. D., and Fairbanks, R. G.: Monsoon-tropical ocean interaction in a network of coral records spanning the 20th century, Mar. Geol., 201, 207-222, 2003.

Cobb, K., Charles, C. D., Cheng, H., and Edwards, R. L.: El NiñoSouthern Oscillation and tropical Pacific climate during the last millenium, Nature, 424, 271-276, 2003.

Cobb, K. M., Westphal, N., Sayani, H. R., Watson, J. T., Di Lorenzo, E., Cheng, H., Edwards, L., and Charles, C. D.: Highly variable El Niño-Southern Oscillation throughout the Holocene, Science, 339, 67-70, 2013

Cook, E. R.: Niño 3 Index Reconstruction, in: International TreeRing Data Bank, IGBP PAGES/World Data Center-A for Paleoclimatology Data Contribution Series, 2000.

Cook, E. R., D’Arrigo, R. D., and Anchukaitis, K. J.: ENSO reconstructions from long tree-ring chronologies: Unifying the differences, in: Talk presented at a special workshop on Reconciling ENSO Chronologies for the Past 500 Years, held in Moorea, French Polynesia on 2-3 April 2008, 2008.

Danabasoglu, G., Bates, S., Briegleb, B. P., Jayne, S. R., Jochum, M., Large, W. G., Peacock, S., and Yeager, S. G.: The CCSM4 ocean component, J. Climate, 25, 1361-1389, 2012.

Davis, R. E.: Predictability of sea surface temperature and sea level pressure anomalies over the North Pacific Ocean, J. Phys. Oceanogr., 6, 249-266, 1976.

DeLong, K. L., Quinn, T. M., Taylor, F. W., Lin, K., and Shen, C. C.: Sea surface temperature variability in the southwest tropical Pacific since AD 1649, Nature Climate Change, 2, 799-804, doi:10.1038/NCLIMATE1583, 2012.

Delworth, T. L., Broccoli, A. J., Rosati, A., Stouffer, R. J., Balaji, V., Beesley, J. A., Cooke, W. F., Dixon, K. W., Dunne, J., Dunne, K. A., Durachta, J. W., Findell, K. L., Ginoux, P., Gnanadesikan, A., Gordon, C. T., Griffies, S. M., Gudgel, R., Harrison, M. J., Held, 
I. M., Hemler, R. S., Horowitz, L. W., Klein, S. A., Knutson, T. R., Kushner, P. J., Langenhorst, A. R., Lee, H.-C., Lin, S.-J., Lu, J., Malyshev, S. L., Milly, P. C. D., Ramaswamy, V., Russell, J., Schwarzkopf, M. D., Shevliakova, E., Sirutis, J. J., Spelman, M. J., Stern, W. F., Winton, M., Wittenberg, A. T., Wyman, B., Zeng, F., and Zhang, R.: GFDL's CM2 global coupled climate models. Part I: Formulation and simulation characteristics, J. Climate, 19, 643-674, 2006.

Deser, C., Phillips, A. S., Tomas, R. A., Okumura, Y. M., Alexander, M. A., Capotondi, A., Scott, J. D., Kwon, Y.-O., and Ohba, M.: ENSO and Pacific Decadal Variability in the Community Climate System Model Version 4, J. Climate, 25, 2622-2651, doi:10.1175/JCLI-D-11-00301.1, 2012.

Dunbar, R., Wellington, G. M., Colgan, M. W., and Glynn, P. W.: Eastern Pacific sea surface temperature since 1600 A.D.: The $\delta^{18} \mathrm{O}$ record of climate variability in Galápagos corals, Paleoceanography, 9, 291-315, 1994.

Emile-Geay, J., Cobb, K. M., Mann, M. E., and Wittenberg, A. T.: Estimating tropical Pacific SST variability over the past millennium. Part 1: Methodology and validation, J. Climate, 26, 2302 2328, doi:10.1175/JCLI-D-11-00510.1, 2013a.

Emile-Geay, J., Cobb, K. M., Mann, M. E., and Wittenberg, A. T.: Estimating tropical Pacific SST variability over the past millennium. Part 2: Reconstructions and uncertainties, J. Climate, 26, 2329-2352, doi:10.1175/JCLI-D-11-00511.1, 2013 b.

Evans, M., Kaplan, A., Cane, M. A., and Villalba, R.: Interhemispheric Climate Linkages, in: Globality and optimality in climate field reconstructions from proxy data, Cambridge Univ. Press, 53-72, 2001.

Evans, M., Kaplan, A., and Cane, M. A.: Pacific sea surface temperature field reconstruction from coral $\delta^{18} \mathrm{O}$ data using reduced space objective analysis, Paleoceanography, 17, 1007, doi:10.1029/2000PA000590, 2002.

Federov, A. V. and Philander, S. G.: Is El Niño changing?, Science, 288, 1997-2002, 2000.

Hereid, K. A., Quinn, T. M., Taylor, F. W., Shen, C.-C., Edwards, R. L., and Cheng, H.: Coral record of reduced El Niño activity in the early 15 th to middle 17 th centuries, Geology, 41, 51-54, doi:10.1130/G33510.1, 2013.

Heiss, G. A.: Coral reefs in the Red Sea: Growth, production and stable isotopes, GEOMAR Report 32, 1-141, 1994.

Isdale, P. J., Stewart, B. J., Tickle, K. S., and Lough, J. M.: Palaeohydrological variation in a tropical river catchment: a reconstruction using fluorescent bands in corals of the Great Barrier Reef, Australia, Holocene, 8, 1-8, doi:10.1191/095968398670905088, 1998.

Kaplan, A., Cane, M., Kushnir, Y., Clement, A., Blumenthal, M., and Rajagopalan, B.: Analyses of global sea surface temperature 1856-1991, J. Geophys. Res., 103, 567-589, 1998.

Karamperidou, C., Cane, M. A., Lall, U., and Wittenberg, A. T.: Intrinsic modulation of ENSO predictability viewed through a local Lyapunov lens, Clim. Dynam., online first, doi:10.1007/s00382013-1759-z, 2013.

Kug, J.-S., Choi, J., An, S.-I., Jin, F.-F., and Wittenberg, A. T.: Warm pool and cold tongue El Niño events as simuilated by the GFDL CM2.1 coupled GCM, J. Climate, 23, 1226-1239, doi:10.1175/2009JCLI3293.1, 2010.

Landrum, L., Otto-Bliesner, B. L., Wahl, E. R., Conley, A., Lawrence, P. J., Rosenbloom, N., and Teng, H.: Last Millennium
Climate and Its Variability in CCSM4, J. Climate, 26, 10851111, doi:10.1175/JCLI-D-11-00326.1, 2013.

Larkin, N. K. and Harrison, D. E.: ENSO Warm (El Niño) and Cold (La Niña) Event Life Cycles: Ocean Surface Anomaly Patterns, Their Symmetries, Asymmetries, and Implications, J. Climate, 15, 1118-1140, 2002.

Le Quesne, C., Stahle, D. W., Cleaveland, M. K., Therrell, M. D., Aravena, J. C., and Barichivich, J.: Ancient Austrocedrus TreeRing Chronologies Used to Reconstruct Central Chile Precipitation Variability from a.d. 1200 to 2000, J. Climate, 19, 57315744, doi:10.1175/JCLI3935.1, 2006.

Li, J., Xie, S.-P., Cook, E. R., Huang, G., D’Arrigo, R., Lui, F., Ma, J., and Zheng, X.-T.: Interdecadal modulation of El Niño amplitude during the past millennium, Nature Climate Change, $1,114-118,2011$

Li, J., Xie, S.-P., Cook, E. R., Morales, M. S., Christie, D. A., Johnson, N. C., Chen, F., D’Arrigo, R., Fowler, A. M., Gou, X., and Fang, K.: El Niño modulations over the past seven centuries, Nature Climate Change, 3, 822-826, doi:10.1038/nclimate1936, 2013.

Linsley, B. K., Dunbar, R. B., and Mucciasone, D. A.: A coralbased reconstruction of Inter-Tropical Convergence Zone variability over Central America since 1707, J. Geophys. Res., 99, 9977-9994, 1994.

Linsley, B. K., Wellington, G. M., and Schrag, D. P.: Decadal Sea Surface Temperature Variability in the Subtropical South Pacific from 1726 to 1997 A.D., Science, 290, 1145, doi:10.1126/science.290.5494.1145, 2000.

Lough, J. M.: Tropical river flow and rainfall reconstructions from coral luminescence: Great Barrier Reef, Australia, Paleoceanography, 22, PA2218, doi:10.1029/2006PA001377, 2007.

Mann, M., Bradley, R. S., and Hughes, M. K.: Multiscale Variability and Global and Regional Impacts, in: Long-term variability in the El Niño-Southern Oscillation and associated teleconnections, Cambridge Univ. Press, 357-412, 2000.

McGregor, S., Timmermann, A., and Timm, O.: A unified proxy for ENSO and PDO variability since 1650, Clim. Past, 6, 1-17, doi:10.5194/cp-6-1-2010, 2010.

Neale, R. B., Richter, J., Park, S., Lauritzen, P. H., Vavrus, S. J., Rasch, P. J., and Zhang, M.: The mean climate of the Community Atmosphere Model (CAM4) in forced SST and fully coupled experiments, J. Climate, 26, 5150-5168, doi:10.1175/JCLI-D-1200236.1, 2013.

Nicholls, N.: Predictability of interannual variations of Australian seasonal tropical cyclone activity, Mon. Weather Rev., 113, 1144-1149, 1985.

Ogata, T., Xie, S.-P., Wittenberg, A., and Sun, D.-Z.: Interdecadal amplitude modulation of El Niño/Southern Osciallation and its impacts on tropical Pacific variabiltiy, J. Climate, online first, doi:10.1175/JCLI-D-12-00415.1, 2013.

Power, S., Casey, T., Folland, C., Colman, A., and Mehta, V.: Interdecadal modulation of the impact of ENSO on Australia, Clim. Dynam., 15, 319-324, 1999.

Quinn, T. M., Taylor, F. W., and Crowley, T. J.: A 173 year stable isotope record from a tropical South Pacific coral, Quaternary Sci. Rev., 12, 407-418, 1993.

Quinn, T. M., Crowley, T. J., Taylor, F. W., Henin, C., Joannot, P., and Join, Y.: A multicentury stable isotope record from a New Caledonia coral: Interannual and decadal sea surface tempera- 
ture variability in the southwest Pacific since 1657 A.D., Paleoceanography, 13, 412-426, 1998.

Rayner, N., Parker, D., Horton, E., Folland, C., Alexander, L., Rowell, D., Kent, E., and Kaplan, A.: Global analyses of sea surface temperature, sea ice, and night marine air temperature since the late nineteenth century, J. Geophys. Res., 108, 4407, doi:10.1029/2002JD002670, 2003.

Shen, G. T., Cole, J. E., Lea, D. W., Linn, L. J., McConnaughey, T. A., and Fairbanks, R. G.: Surface ocean variability at Galapagos from 1936-1982: calibration of geochemical tracers in corals, Paleoceanography, 7, 563-588, 1992.

Smith, R., Jones, P., Briegleb, B., Bryan, F., Danabasoglu, G., Dennis, J., Dukowicz, J., Eden, C., Fox-Kemper, B., Gent, P., Hecht, M., Jayne, S., Jochum, M., Large, W., Lindsay, K., Maltrud, M., Norton, N., Peacock, S., Vertenstein, M., and Yeager, S.: The Parallel Ocean Program (POP) reference manual, Los Alamos National Laboratory Tech. Rep., LAUR-10-01853, 141 pp., 2010.

Smith, T. M., Reynolds, R. W., Peterson, T. C., and Lawrimore, J.: Improvements to NOAA's Historical Merged Land-Ocean Surface Temperature Analysis (1880-2006), J. Climate, 21, $2283-$ 2296, 2008.

Stahle, D., D’Arrigo, R. D., Krusic, P. J., Cleaveland, M. K., Cook, E. R., Allan, R. J., Cole, J. E., Dunbar, R. D., Therrell, M. D., Gay, D. A., Moore, M. D., Stokes, M. A., Burns, B. T., Villanueva-Diaz, J., and Thompson, L. G.: Experimental dendroclimatic reconstruction of the Southern Oscillation, B. Am. Meteorol. Soc., 79, 2137-2152, 1998.
Timmermann, A., Jin, F.-F., and Abshagen, J.: A non-linear theory for El Niño bursting, J. Atmos. Sci., 60, 152-165, 2003.

Wilson, R., Cook, E., D’Arrigo, R., Riedwyl, N., Evans, M. E., Tudhope, A., and Allan, R.: Reconstructing ENSO: the influence of method, proxy data, climate forcing and teleconnections, J. Quat. Sci., 25, 62-78, 2010.

Wittenberg, A.: Are historical records sufficient to constrain ENSO simulations?, Geophys. Res. Lett., 36, L12702, doi:10.1029/2009GL038710, 2009.

Wittenberg, A. T., Rosati, A., Lau, N.-C., and Ploshay, J. J.: GFDL's CM2 global coupled climate models. Part III: Tropical Pacific climate and ENSO, J. Climate, 19, 698-722, 2006.

Wolff, C., Haug, G. H., Timmermann, A., Sinninghe Damsté, J. S., Brauer, A., Sigman, D. M., Cane, M. A., and Verschuren, D.: Reduced Interannual Rainfall Variability in East Africa During the Last Ice Age, Science, 333, 743-747, 2011.

Zhang, R. H., Rothstein, L. M., and Busalacchi, A. J.: Origin of upper-ocean warming and El Niño change on decadal scales in the tropical Pacific Ocean, Nature, 391, 879-883, 1998. 